\title{
BMJ Open Early Life Exposure in Mexico to ENvironmental Toxicants (ELEMENT) Project
}

\author{
Wei Perng, ${ }^{1,2,3}$ Marcela Tamayo-Ortiz, ${ }^{4}$ Lu Tang, ${ }^{5}$ Brisa N Sánchez, ${ }^{5}$ \\ Alejandra Cantoral, ${ }^{4}$ John D Meeker, ${ }^{6}$ Dana C Dolinoy, ${ }^{2,6,7}$ Elizabeth F Roberts, ${ }^{8}$ \\ Esperanza Angeles Martinez-Mier, ${ }^{9}$ Hector Lamadrid-Figueroa, ${ }^{10}$ Peter X K Song, ${ }^{5}$ \\ Adrienne S Ettinger, ${ }^{2}$ Robert Wright, ${ }^{11}$ Manish Arora, ${ }^{11}$ Lourdes Schnaas, ${ }^{12}$ \\ Deborah J Watkins, ${ }^{6}$ Jaclyn M Goodrich, ${ }^{6}$ Robin C Garcia, ${ }^{2}$ \\ Maritsa Solano-Gonzalez, ${ }^{13}$ Luis F Bautista-Arredondo, ${ }^{13}$ \\ Adriana Mercado-Garcia, ${ }^{13}$ Howard Hu, ${ }^{14}$ Mauricio Hernandez-Avila, ${ }^{15}$ \\ Martha Maria Tellez-Rojo, ${ }^{13}$ Karen E Peterson ${ }^{2,6}$
}

To cite: Perng W, TamayoOrtiz M, Tang L, et al. Early Life Exposure in Mexico to ENvironmental Toxicants (ELEMENT) Project. BMJ Open 2019;9:e030427. doi:10.1136/ bmjopen-2019-030427

- Prepublication history for this paper is available online. To view these files, please visit the journal online (http://dx.doi org/10.1136/bmjopen-2019030427).

WP and MT- 0 contributed equally.

Received 14 March 2019

Revised 23 July 2019

Accepted 25 July 2019
Check for updates

(C) Author(s) (or their employer(s)) 2019. Re-use permitted under CC BY-NC. No commercial re-use. See rights and permissions. Published by BMJ.

For numbered affiliations see end of article.

Correspondence to Dr Martha Maria Tellez-Rojo; mmtellez@insp.mx

\section{ABSTRACT}

Purpose The Early Life Exposure in Mexico to

ENvironmental Toxicants (ELEMENT) Project is a motherchild pregnancy and birth cohort originally initiated in the mid-1990s to explore: (1) whether enhanced mobilisation of lead from maternal bone stores during pregnancy poses a risk to fetal and subsequent offspring neurodevelopment; and (2) whether maternal calcium supplementation during pregnancy and lactation can suppress bone lead mobilisation and mitigate the adverse effects of lead exposure on offspring health and development. Through utilisation of carefully archived biospecimens to measure other prenatal exposures, banking of DNA and rigorous measurement of a diverse array of outcomes, ELEMENT has since evolved into a major resource for research on early life exposures and developmental outcomes.

Participants $n=1643$ mother-child pairs sequentially recruited (between 1994 and 2003) during pregnancy or at delivery from maternity hospitals in Mexico City, Mexico.

Findings to date Maternal bone (eg, patella, tibia) is an endogenous source for fetal lead exposure due to mobilisation of stored lead into circulation during pregnancy and lactation, leading to increased risk of miscarriage, low birth weight and smaller head circumference, and transfer of lead into breastmilk. Daily supplementation with $1200 \mathrm{mg}$ of elemental calcium during pregnancy and lactation reduces lead resorption from maternal bone and thereby, levels of circulating lead. Beyond perinatal outcomes, early life exposure to lead is associated with neurocognitive deficits, behavioural disorders, higher blood pressure and lower weight in offspring during childhood. Some of these relationships were modified by dietary factors; genetic polymorphisms specific for iron, folate and lipid metabolism; and timing of exposure. Research has also expanded to include findings published on other toxicants such as those associated with personal care products and plastics (eg, phthalates, bisphenol A), other metals (eg, mercury, manganese, cadmium), pesticides (organophosphates) and fluoride; other biomarkers (eg, toxicant levels in plasma, hair and teeth); other outcomes (eg, sexual maturation, metabolic
Strengths and limitations of this study

- In-person collection of exposure and outcome measures using research-quality standard protocols.

- Extensive biorepository of specimens from gestation through adolescence.

- Rich covariate data including physician-assessed pubertal status, newly collected high-dimensional 'omics data and ethnographical data.

- Limited information on maternal perinatal conditions (eg, data on prepregnancy body mass index in a small subset of mothers, no information on maternal glycaemia).

- Potential non-generalisability of results to those of other race/ethnicities.

syndrome, dental caries); and identification of novel mechanisms via epigenetic and metabolomics profiling. Future plans As the ELEMENT mothers and children age, we plan to (1) continue studying the long-term consequences of toxicant exposure during the perinatal period on adolescent and young adult outcomes as well as outcomes related to the original ELEMENT mothers, such as their metabolic and bone health during perimenopause; and (2) follow the third generation of participants (children of the children) to study intergenerational effects of in utero exposures.

Trial registration number NCT00558623.

\section{INTRODUCTION}

Why was the cohort set up?

Original cohorts

In the early 1990 s, a series of epidemiological studies on the detrimental effects of childhood lead exposure on neurodevelopment ${ }^{1-4}$ and an emerging concern on the neurotoxic effects of prenatal lead exposure ${ }^{5}$ motivated $\mathrm{HH}, \mathrm{MH}-\mathrm{A}$ and Eduardo Palazuelos (EP) to 
explore the two original research questions of the Early Life Exposure to ENvironmental Toxicants (ELEMENT) Project: (1) Does enhanced mobilisation of lead from maternal bone stores during pregnancy pose a risk to fetal development and subsequent offspring neurodevelopment $t^{5}$; (2) Can calcium supplementation during early-life suppress the mobilisation of lead from maternal bone and mitigate the adverse health effects of lead exposure ${ }^{6}$ ? These inquiries were critically important given high levels of lead exposure in several countries worldwide $^{78}$ including Mexico ${ }^{9}$; biological evidence of enhanced bone mobilisation (and thus, mobilisation of lead stored in bone) during the in utero and postpartum lactation periods; ${ }^{10} 11$ and growing evidence of vulnerability during the fetal and infancy life stages to environmental exposures in relation to a range of health outcomes. ${ }^{12-14}$ Together, these concerns stimulated the search for cost-effective and population-level intervention strategies to mitigate the adverse effects of lead.

Mexico City was an ideal setting to address these questions for two key reasons. First, because the phase-out of leaded gasoline in Mexico occurred later than in the USA, ${ }^{915}$ levels of lead in bone were expected to be higher in women in Mexico. Second, even after the phase-out of leaded gasoline, blood lead concentrations among children in Mexico City remained three to four times higher than that of children in the USA ${ }^{16}$ due, in large part, to continued use of lead-glazed ceramics, which remains prevalent in Mexico, especially in the central and southern regions of the nation. While unfortunate from a population health perspective, the relatively high lead exposure in Mexico City provided a powerful context within which to explore the first research question, especially given that k-X-ray fluorescence (KXRF), a non-invasive technology for measuring bone lead levels, had recently become available. ${ }^{17}$ Thus, in 1993, HH, MHA and EP founded the ELEMENT Project. Additional investigators, including KEP (current principal investigator(PI) in the USA) and M-MT-R (current PI in Mexico) became involved as the project expanded.

Today, ELEMENT has become a 20+ year international multi-institutional partnership. The ELEMENT Project is based on three sequentially recruited distinct cohorts of mother-child pairs recruited from a homogenous low-income to middle-income population attending family clinics in Mexico City, most belonging to the Instituto Mexicano del Seguro Social (IMSS). Cohort 1 (recruited 19941995) was a prospective study of measures of maternal and fetal lead biomarkers, determinants of levels of lead in the biomarkers and perinatal outcomes coupled with a postnatal randomised placebo-controlled trial (RCT). The trial, which focused on lactating women, sought to examine the impact of early life lead exposure on neurobehavioural and physical developmental outcomes and the potential modifying effect of a daily $1200 \mathrm{mg}$ calcium supplementation on biomarkers of lead in maternal blood and breast milk while breast feeding. ${ }^{18}$ Cohort 2 (recruited 1997-2000) was initiated, in part, based on findings from cohort 1 and was an observational cohort study that examined the relationship between periconceptional and gestational maternal blood, plasma and bone lead biomarkers in two different groups of women with follow-up of offspring neurocognitive outcomes. Cohort 3 (recruited 2001-2003) was an RCT with similar goals to that of cohort 1 , but with the goal of assessing effects of calcium supplementation during pregnancy (table 1).

Background and sociodemographic characteristics of the three original cohorts are similar, as shown in table 2, with the exception of delivery mode wherein vaginal deliveries were of highest prevalence in cohort 2B. In analyses involving multiple cohorts, researchers evaluated for potential heterogeneity across cohorts by examining bivariate associations of key study characteristics by cohort membership, followed by covariate adjustment for cohort membership or inclusion of a random effect for cohort if appropriate. ${ }^{19} 20$ Additionally, development of more sophisticated statistical methods is underway to deal with heterogeneity across cohorts. ${ }^{21} 22$

These cohorts comprise 1643 mother-child pairs, some of whom we have followed for over two decades. Findings from these cohorts motivated the reduced use of lead in consumer products in Mexico ${ }^{2324}$ and informed US lead exposure and management guidelines. ${ }^{25-28}$

Maternal informed consent and child assent were provided for all participants. The institutional review boards of the Mexico National Institute of Public Health (CI-03121993, CI-124-30052000, CI-362-16122003, CI-59913062007, CI-599-2-07112010, CI-599-17072014, CI-5999-15102014, CI-599-8-14102014, CI-599-3-23062014, CI-1377-15062016, CI-1594-18122018), Harvard School of Public Health (P10345-107/9910CONT) and the University of Michigan approved research protocols (\#HUM00034344, HUM00155958).

\section{Follow-up studies}

\section{ELEMENT 2008}

In 2008, we pooled together mother-child pairs from the original cohorts to study interactions of perinatal lead exposure and polymorphisms of genes relevant to cholesterol metabolism and their influence on offspring neurodevelopment and behaviour at age $6-15$ years.

\section{ELEMENT 2011}

Between 2011 and 2012, we re-recruited a convenience sample (based on availability of prenatal biological samples) of offspring from cohorts 2 and 3 for participation in follow-up studies concerned with: (1) whether prenatal and peripubertal exposure to endocrine disrupting chemicals (EDCs) were associated with obesity, metabolic risk and onset of sexual maturation at age 8-15 years; and (2) to examine epigenetic, metabolomics and oxidative stress as mechanisms linking EDC exposure to health outcomes.

\section{ELEMENT 2014}

In 2014, we commenced ethnographic observations of six families (the 'Mexican Exposures Project') to obtain a 
Table 1 Original ELEMENT cohorts and follow-up history

\section{Study information}

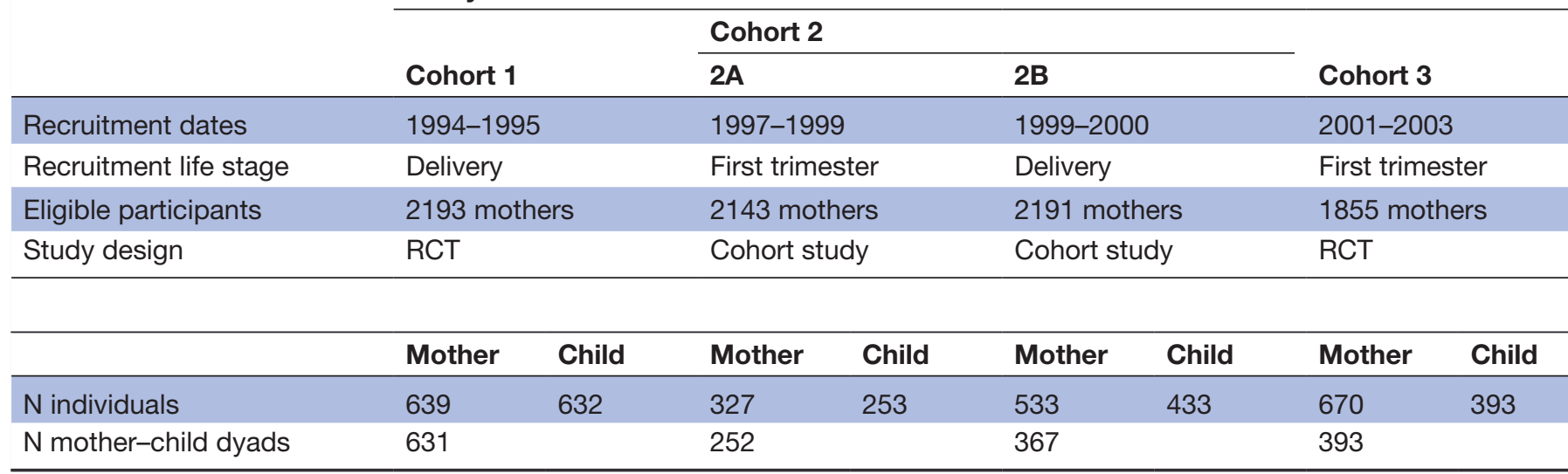

\section{Follow-up visits for the original cohorts}

\begin{tabular}{|c|c|c|c|c|c|c|c|c|}
\hline \multicolumn{9}{|l|}{ Pregnancy } \\
\hline First trimester & & & $x$ & & & & $x$ & \\
\hline Second trimester & & & $x$ & & & & $x$ & \\
\hline Third trimester & & & $x$ & & & & $x$ & \\
\hline Delivery & $x$ & $x$ & $x$ & $x$ & $x$ & $x$ & $x$ & $\mathrm{x}$ \\
\hline \multicolumn{9}{|l|}{ Postpartum months } \\
\hline 1 & $x$ & $x$ & $x$ & . & $x$ & & $x$ & \\
\hline 3 & $x$ & $x$ & & $x$ & & $x$ & $x$ & $x$ \\
\hline 4 & & & $\mathrm{x}$ & & & & & \\
\hline 5 & & $x$ & & & & & $x$ & \\
\hline 6 & & & & $x$ & & $x$ & & $\mathrm{x}$ \\
\hline 7 & $x$ & $x$ & $x$ & & & . & $x$ & \\
\hline 9 & & & & & & & $x$ & \\
\hline 11 & & & & & & & $x$ & \\
\hline 12 & & $x$ & $x$ & $x$ & & $x$ & $x$ & $\mathrm{x}$ \\
\hline 18 & & $x$ & & $x$ & & $x$ & & $x$ \\
\hline 24 & & $x$ & & $x$ & & $x$ & & $\mathrm{x}$ \\
\hline 30 & & $x$ & & $x$ & & $x$ & & $x$ \\
\hline 36 & & $x$ & & $x$ & & $x$ & & $\mathrm{x}$ \\
\hline 42 & & $x$ & & & & & & \\
\hline 48 & & $x$ & & $x$ & & $x$ & & $x$ \\
\hline 60 & & & & $x$ & & $x$ & & \\
\hline
\end{tabular}

Total mothers $=2169$; total children $=1711$.

ELEMENT, Early Life Exposure in Mexico to ENvironmental Toxicants; RCT, randomised placebo-controlled trial.

fuller picture of how chemical exposures and the changing food environment in Mexico City impact health. ${ }^{29}{ }^{30}$ This study provided a context for mixed-methods approaches as we continue to follow participants over their life course and a platform for combining ethnographic and biomarker data about ELEMENT participants. Building off of this project, we recently began multidisciplinary home visit study called 'Neighbourhood Environments as Socio-Techno-Bio Systems: Water Quality, Public Trust and Health in Mexico City (NESTSMX)' with 60 ELEMENT families. The aim of the study is to combine ethnographic and environmental health and environmental engineering to understand household water management, water trust and water quality.

\section{ELEMENT 2015}

Between 2015 and 2018, we followed-up children in ELEMENT 2011 through late adolescence and included additional similarly aged participants from the original cohorts. Goals of this study were similar in scope to ELEMENT 2011, but included new research foci: (1) characterising long-term consequences of early life exposure 
Table 2 Characteristics of the original ELEMENT cohort participants

\begin{tabular}{|c|c|c|c|c|}
\hline & \multicolumn{4}{|c|}{ Mean \pm SD or $\%$} \\
\hline & \multirow[b]{2}{*}{ Cohort 1} & \multicolumn{2}{|l|}{ Cohort 2} & \multirow[b]{2}{*}{ Cohort 3} \\
\hline & & $2 A$ & 2B & \\
\hline Maternal characteristics & $n=639$ & $\mathrm{n}=327$ & $n=533$ & $n=670$ \\
\hline Age at enrolment (years) & $24.6 \pm 5.1$ & $26.9 \pm 5.3$ & $25.2 \pm 5.1$ & $26.4 \pm 5.5$ \\
\hline Gestational age at enrolment (weeks) & $39.1 \pm 1.6$ & $15.4 \pm 5.9$ & $38.9 \pm 1.3$ & $13.1 \pm 2.1$ \\
\hline \multicolumn{5}{|l|}{ Marital status (\%) } \\
\hline Married or cohabiting & 91.10 & 91.10 & 93.30 & 88.50 \\
\hline Single & 8.90 & 8.90 & 6.70 & 11.50 \\
\hline Maternal education (years) & $9.34 \pm 3.1$ & $10.75 \pm 3.2$ & $10.84 \pm 3.0$ & $10.7 \pm 2.9$ \\
\hline \multicolumn{5}{|l|}{ Parity (including index birth) (\%) } \\
\hline 0 & 0 & 1.50 & 0 & 0 \\
\hline $1-2$ & 73.60 & 70.90 & 78.40 & 70.40 \\
\hline$\geq 3$ & 26.40 & 27.50 & 21.60 & 29.60 \\
\hline Smoked during pregnancy (\%) & 4.30 & 4.00 & 9.50 & 2.20 \\
\hline Calcium treatment $(\%, \mathrm{~N})$ & 47.00 & N/A & N/A & 50.00 \\
\hline \multicolumn{5}{|l|}{ Delivery method (\%) } \\
\hline Vaginal & 77.30 & 46.20 & 91.10 & 50.70 \\
\hline Forceps & 1.70 & 3.50 & 3.40 & 1.10 \\
\hline C-section & 19.70 & 40.00 & 5.00 & 21.30 \\
\hline Missing & 1.30 & 12.80 & 0.40 & 26.90 \\
\hline Offspring characteristics at delivery & $n=632$ & $n=253$ & $n=433$ & $n=393$ \\
\hline \multicolumn{5}{|l|}{$\operatorname{Sex}(\%)$} \\
\hline Male & 54.50 & 51.90 & 54.10 & 49.40 \\
\hline Female & 45.50 & 48.10 & 45.90 & 50.60 \\
\hline Gestational age at delivery (weeks) & $39.2 \pm 1.5$ & $38.6 \pm 1.9$ & $39.0 \pm 1.2$ & $38.6 \pm 1.7$ \\
\hline Birth weight (g) & $3153 \pm 474$ & $3102 \pm 531$ & $3130 \pm 484$ & $3131 \pm 484$ \\
\hline
\end{tabular}

ELEMENT, Early Life Exposure in Mexico to ENvironmental Toxicants.

to fluoride; (2) exploring epigenetic and metabolomics mechanisms.

\section{Pilot studies}

In addition to the many pilot studies conducted in the past, two recent pilot studies are currently underway at the time of writing and will soon reach completion. Although we do not formally describe participants of these cohorts in this article, we provide a description of study goals and sample sizes below and in figure 1 .

\section{ELEMENT 2016}

Between 2016 and 2017, 100 offsprings from cohort 1 were recruited for MRI of hepatic fat fraction to identify determinants of fatty liver during young adulthood.

\section{ELEMENT 2017}

We recruited 101 mothers from all three cohorts to evaluate associations of chemical exposures during pregnancy and later adulthood with metabolic and bone health (measured via intelligent dual X-ray absorptiometry) during the perimenopausal period.

\section{COHORT DESCRIPTION}

Who is in the cohort?

Table 2 shows characteristics of participants in the original cohorts. Table 1 and figure 1 summarise study design, recruitment timing and number of eligible and enrolled participants, with added details on the follow-up and pilot studies in the figure. Inclusion criteria included healthy women in Mexico City with a normal pregnancy and/or delivery, intention to breast feed and no previous diagnoses of severe disease. We excluded women if they had a non-singleton birth, a history of preeclampsia or pregnancy-related hypertension, psychiatric or cardiac disease, diagnosis of gestational diabetes, a history of repeated urinary tract infections or seizure disorders requiring daily medication. The same research team followed all cohorts, using the same facilities, questionnaires and protocols. 


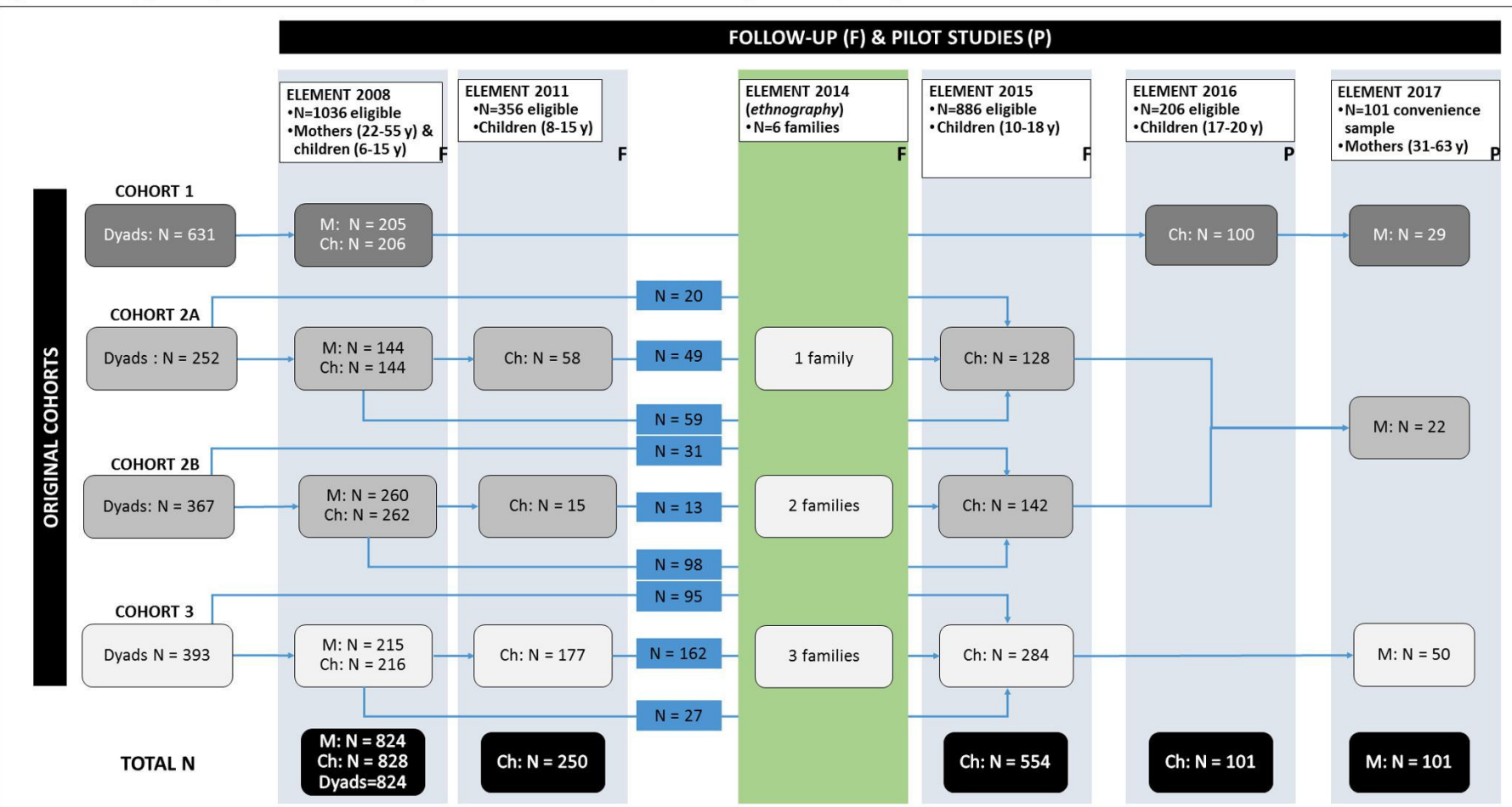

Figure 1 Study participant flow for the original ELEMENT cohorts, follow-up studies and pilot studies. Ch, children; ELEMENT, Early life exposure in Mexico to ENvironmental toxicants; F, follow-up study; M, mothers; P, pilot study.

In the section below, we describe participant characteristics for the original three cohorts and key follow-up studies (ELEMENT 2008, 2011, and 2015).

\section{Original cohorts}

As outlined in table 1, between January 1994 and June 1995, we interviewed 2945 women admitted for labour and delivery for cohort 1 . Of them, 2193 were eligible for the study and $639(45.5 \%)$ agreed to participate. After excluding 22 who stopped breast feeding by 1 month postpartum, the remaining 617 women were randomly assigned to receive $1200 \mathrm{mg}$ of elemental calcium per day $(\mathrm{n}=296)$ versus a placebo $(\mathrm{n}=321)$.

Cohort 2 comprises two different groups of women. For cohort 2A (recruitment 1997-1999), we interviewed 2215 women before pregnancy or during the first trimester. Of the 2143 eligible women, 327 were recruited. Cohort 2B includes 533 women recruited from 1999 to 2000 at delivery (2191 eligible and 2194 interviewed). Exclusion criteria for cohort 2 were similar to cohort 1 , but also included missing data on cord blood lead or cord blood lead $>10 \mu \mathrm{g} / \mathrm{dL}$, conditions interfering with calcium metabolism, conditions associated with low birth weight, gestational age of $<37$ weeks, admittance to the neonatal intensive care unit, infant Apgar score of $\leq 6$, birth weight $<2000 \mathrm{~g}$ or serious birth defects.

Following findings from cohort 1 that calcium supplementation reduced maternal blood lead by $15 \%-20 \%^{18}$ and breast milk lead by $5 \%-10 \%,{ }^{31}$ and results of cohort 2 , which clarified the relationship between lead in whole blood versus plasma, ${ }^{32-34}$ we initiated cohort 3 to examine effects of calcium supplementation on blood lead levels during pregnancy. For cohort 3, we recruited women between 2001 and 2003 from IMSS family clinics. Eligibility criteria included gestational age $<14$ weeks; no hypertensive disorders, history of type 1 or 2 diabetes or gestational diabetes; and planned residence in the Mexico City area for the next 5 years. Of the 3837 women interviewed, 1855 eligible women were eligible, $36 \%(\mathrm{n}=670)$ of whom agreed to participate and were randomised to receive $1200 \mathrm{mg}$ calcium per day $(\mathrm{n}=334)$ or a placebo $(\mathrm{n}=336)$.

\section{Follow-up studies}

\section{ELEMENT 2008}

Of the 1036 eligible children between 6 and 15 years of age from the original three cohorts, we excluded participants born $<37$ gestational weeks, those with birth weight $<2000 \mathrm{~g}$ and Apgar score $\leq 6$, admittance to the neonatal intensive care unit or a serious birth defect, arriving at a final sample size of 824 mother-child pairs.

\section{ELEMENT 2011}

Between 2011 and 2012, we recontacted 250 children and adolescents from cohorts 2 and 3. Criteria for eligibility included availability of archived maternal urine and cordblood for toxicant assays of interest and offspring age between 8 and 15 years.

\section{ELEMENT 2015}

In 2015, we rerecruited 224 of 250 ELEMENT 2011 participants. We also recruited 330 additional offsprings who were of similar age to ELEMENT 2011 participants, giving 
priority to those who had archived cord blood and urine samples and/or having been part of ELEMENT 2008. Additional data collected for 2015 included physical activity and sleep data from accelerometers; measures of fluoride exposure in food/beverages, water and plasma; and dental examinations for caries, enamel fluorosis and hypomineralisation.

\section{How often have the cohorts been followed-up?}

Depending on the specific cohort, women were interviewed two to four times during the first postpartum year. Offsprings were assessed every 6 months during their first four (cohort 1 ) or five (cohorts 2 and 3 ) years of life, with one to two follow-up visits at ages $6-15$ years in ELEMENT 2008, once at ages 8-15 years in ELEMENT 2011 and twice at 10-18 years in ELEMENT 2015. Table 1 and figure 1 provide an overview of the timing of research visits.

\section{WHAT HAS BEEN MEASURED?}

While some of the specific measures differ across the original cohorts and follow-up studies, there are several key assessments common across studies. These common assessments include: (1) assessment of lead exposure (blood lead concentration from maternal venous, child venous and umbilical cord samples using graphite furnace atomic absorption spectroscopy until the late 2000s; then, inductively coupled plasma mass spectrometry; all in laboratories participating in the quality assurance/ quality control (QA/QC) protocols of the US Centres for Disease Control and the State of Wisconsin; breastmilk lead concentration via mass spectrometry ${ }^{35}$ ) and maternal bone lead levels using a KXRF instrument ${ }^{1736}$; (2) dietary intake via a food frequency questionnaire that has been validated for use among women living in Mexico City $^{37}$; (3) evaluation of neurobehavioural development in the offspring, including intelligence using the Bayley Scales of Infant Development (BSID-II, translated into Spanish $^{38}$ ) in the early years, McCarthy Scales of Children Abilities (MSCA, Spanish version) around age 4 years $^{39}$ ), Wechsler Abbreviated Scale of Intelligence (WAIS, Spanish version ${ }^{40}$ ) and behaviour using the Behaviour Assessment System for Children (BASC-2, Spanish version $^{41}$ ), executive function using the Behaviour Rating Inventory of Executive Function (BRIEF) ${ }^{42}$; (4) anthropometry and body composition assessment in offspring (weight via a digital scale, height via a calibrated stadiometer, waist circumference via a non-stretchable measuring tape, skinfolds via calibrated callipers and body composition via bioimpedance analysis); (5) sexual maturation of offspring via physician-assessed Tanner staging; (6) blood pressure (left arm resting systolic and diastolic blood pressure of the mother and the child) using a standard mercury column sphygmomanometer; (7) sociodemographic information via an in-house questionnaire. Table 3 summarises details of these and other research measures from each of the original cohorts, follow-up studies and pilot studies.

\section{Patient and public involvement}

During all ELEMENT research visits, a board-certified MD communicates results of tests and measurements (ie, bone lead levels, fasting glucose, lipid profile, body mass index, waist circumference) to the participants and their caregivers in order to facilitate understanding of the values in the context of normal ranges and standards. We engage in community outreach and translation via brochures and information sheets that discuss implications of our research findings in lay language. For example, in 2010, we worked with collaborators at the Instituto Nacional de Salud Pública (INSP) to develop a brochure with information on the dangers of lead exposure and ways to avoid it. This brochure was distributed to the study participants. Subsequently, we adapted this brochure for distribution to the Mexican-American community in southeast Michigan where lead exposure remains a concern. Finally, we are in the process of developing a quarterly newsletter to communicate key findings from current research in ELEMENT to the study participants. In 2014, we implemented a 'Satisfaction Perception Questionnaire' inquiring on participants' perceptions and understanding of ELEMENT Project research questions, their involvement in the studies and their suggestions for improvement in study design and communication of study findings. This has helped us improve our incentives and the quality and depth of the information we give back to the participants. Additionally, as part of ELEMENT 2015 wherein dental examinations were conducted, a certified dentist on the research team discusses examination results with the participants, including explanations of the fluorosis dental images and tailored dental care advice.

\section{FINDINGS TO DATE}

ELEMENT research has generated $>90$ published papers as of this writing; the following captures a sample of ELEMENT's findings. A full list of ELEMENT publications can be found here: https://sph.umich.edu/cehc/ research/publications.html

\section{Health consequences of perinatal exposure to lead \\ Perinatal outcomes}

Characterising lead exposure and prevention of lead mobilisation from maternal bone have been key foci of ELEMENT. ${ }^{26}$ We identified glazed ceramics as a major source of lead in this population ${ }^{43}$ and discovered that maternal bone lead (eg, patella and tibia) was an endogenous source of fetal exposure due to mobilisation of stored lead into circulation ${ }^{32} 34$ during pregnancy and lactation, ${ }^{45} 46$ thereby increasing the risk of miscarriage, ${ }^{33}$ lower birth weight and less weight gain at 1 month after birth, ${ }^{47}$ smaller head circumference and shorter birth length, ${ }^{48}$ and transfer of lead into breastmilk. ${ }^{49}$ Calcium supplementation counteracted these adverse physiological events by reducing lead resorption, ${ }^{50}$ blood lead 
Table 3 Summary of data (denoted as 'measure of interest (tool used)') collected from the ELEMENT cohorts, follow-up studies and pilot studies

\section{Mothers}

\section{Children}

Cohort 1 (delivery through 48 months postpartum)

$\begin{array}{lll}\text { Biospecimen } & \text { Blood } & \text { Cord blood } \\ & \text { Urine } & \end{array}$

$\begin{array}{lll}\text { Questionnaire } & \begin{array}{l}\text { Sociodemographic information (in-house } \\ \text { questionnaire) } \\ \text { Diet (FFQ) }\end{array} & \text { Cognition (BSID-II) } \\ & \text { Home environment (HOME) } & \text { IQ (WAIS) } \\ & \text { IQ (WAIS) } & \text { Neurodevelopment (McCarthy) } \\ \text { Assessments } & \text { Bone lead levels (KXRF) } & \text { Anthropometry (weight, length/height) } \\ & \text { Anthropometry (weight, height) } & \text { Blood pressure } \\ & \text { Blood pressure (manual auscultatory monitor) } & \end{array}$

Cohort 2 (first trimester (2A) or delivery (2B) through 60 months postpartum)

\begin{tabular}{|c|c|c|}
\hline \multirow[t]{3}{*}{ Biospecimen } & Blood & Cord blood \\
\hline & Urine & Blood \\
\hline & Breastmilk & \\
\hline \multirow[t]{5}{*}{ Questionnaire } & $\begin{array}{l}\text { Sociodemographic information (in-house } \\
\text { questionnaire) }\end{array}$ & Cognition (BSID-II) \\
\hline & $\operatorname{Diet}(\mathrm{FFQ})$ & IQ (WAIS) \\
\hline & Home environment (HOME) & Neurodevelopment (McCarthy) \\
\hline & IQ (WAIS) & Behaviour (BASC) \\
\hline & & Diet (FFQ) \\
\hline \multirow[t]{3}{*}{ Assessments } & Bone lead levels (KXRF) & Anthropometry (weight, length/height) \\
\hline & Anthropometry (weight, height) & Blood pressure (manual auscultatory monitor) \\
\hline & Blood pressure (manual auscultatory monitor) & \\
\hline \multicolumn{3}{|c|}{ Cohort 3 (first trimester through 48 months postpartum) } \\
\hline \multirow[t]{3}{*}{ Biospecimen } & Blood & Cord blood \\
\hline & Urine & Blood \\
\hline & Breastmilk & \\
\hline \multirow[t]{5}{*}{ Questionnaire } & $\begin{array}{l}\text { Sociodemographic information (in-house } \\
\text { questionnaire) }\end{array}$ & Cognition (BSID-22) \\
\hline & Diet (FFQ) & Behaviour (BASC) \\
\hline & Home environment (HOME) & IQ (WAIS) \\
\hline & IQ (WAIS) & Neurodevelopment (McCarthy) \\
\hline & & Diet (FFQ) \\
\hline \multirow[t]{4}{*}{ Assessments } & Bone lead levels (KXRF) & Anthropometry (weight, length/height) \\
\hline & Anthropometry (weight, height) & Blood pressure (manual auscultatory monitor) \\
\hline & Blood pressure (manual auscultatory monitor) & \\
\hline & Densitometry (BodPod) & \\
\hline \multicolumn{3}{|c|}{ ELEMENT 2008 (offspring age 6-15 years) } \\
\hline \multirow[t]{3}{*}{ Biospecimen } & Blood & Blood \\
\hline & Urine & Urine \\
\hline & Hair & Hair \\
\hline Questionnaire & $\begin{array}{l}\text { Sociodemographic information (in-house } \\
\text { questionnaire) }\end{array}$ & Cognition (CANTAB) \\
\hline
\end{tabular}


Table 3 Continued

\begin{tabular}{|c|c|c|}
\hline & Mothers & Children \\
\hline & Diet (FFQ) & enrolment (BASC) \\
\hline & Home environment (HOME) & IQ (WAIS) \\
\hline & IQ (WAIS) & Attention (CPT-2) \\
\hline & & Executive function (BRIEF) \\
\hline & & Pre-pulse inhibition \\
\hline & & Diet (FFQ) \\
\hline & & Sexual maturation (self-reported Tanner stage) \\
\hline Assessments & $\begin{array}{l}\text { Anthropometry (weight, height, waist circumference, } \\
\text { skinfold thicknesses) }\end{array}$ & $\begin{array}{l}\text { Anthropometry (weight, height, waist circumference, } \\
\text { skinfold thicknesses) }\end{array}$ \\
\hline & Bone lead levels (KXRF) & Blood pressure (manual auscultatory monitor) \\
\hline ELEMENT 2011( & fspring age $8-15$ years) & \\
\hline Biospecimen & & Blood \\
\hline & & Urine \\
\hline Questionnaire & & Diet (FFQ) \\
\hline & & $\begin{array}{l}\text { Sexual maturation (self-reported Tanner stage + } \\
\text { physician evaluation) }\end{array}$ \\
\hline & & Physical activity (IPAQ) \\
\hline Assessments & & $\begin{array}{l}\text { Anthropometry (weight, length, waist circumference, } \\
\text { skinfold thicknesses) }\end{array}$ \\
\hline & & Blood pressure (automated oscillometric monitor) \\
\hline & & $\begin{array}{l}\text { Sexual maturation (self-reported Tanner stage }+ \\
\text { physician evaluation) }\end{array}$ \\
\hline
\end{tabular}

\section{ELEMENT 2014}

(Ethnography)

Open-ended, long-term observations about everyday life. We collected intensive ethnographic observations about six ELEMENT families and their neighbours for 6 months each from 2014 to 2015. We continue these ongoing observations intermittently.

\section{ELEMENT 2015}

(offspring age

13-20 years)

$\begin{array}{ll}\text { Biospecimen } & \text { Blood } \\ & \text { Urine } \\ \text { Questionnaire } & \text { Toenails } \\ & \text { Shed teeth } \\ \text { Sociodemographic information (in-house } \\ \text { questionnaire) }\end{array}$


Table 3 Continued

\begin{tabular}{|c|c|c|}
\hline & \multirow[t]{3}{*}{ Mothers } & \multirow{2}{*}{$\begin{array}{l}\text { Children } \\
\text { Dental imaging (fluorescent imaging) }\end{array}$} \\
\hline & & \\
\hline & & Accelerometry (Actigraph GTx3) \\
\hline \multicolumn{2}{|l|}{ Biospecimen } & Blood \\
\hline \multirow[t]{2}{*}{ Questionnaire } & & Diet (FFQ) \\
\hline & & $\begin{array}{l}\text { Sociodemographic information (in-house } \\
\text { questionnaire) }\end{array}$ \\
\hline \multirow[t]{3}{*}{ Measurements } & & Anthropometry (weight, length, waist circumference) \\
\hline & & Blood pressure (automated oscillometric monitor) \\
\hline & & Liver fat content (MRI) \\
\hline \multirow[t]{4}{*}{ Questionnaire } & $\begin{array}{l}\text { Sociodemographic information (in-house } \\
\text { questionnaire) }\end{array}$ & \\
\hline & Diet (FFQ) & \\
\hline & Health history (in-house questionnaire) & \\
\hline & Physical activity (IPAQ) & \\
\hline \multirow[t]{3}{*}{ Measurements } & Anthropometry (weight, height, waist circumference) & \\
\hline & Body composition (iDXA, BIA) & \\
\hline & Bone density (iDXA) & \\
\hline
\end{tabular}

BASC, Behavior Assessment System for Children; BIA, Bioelectric Impedance Assessment of Body Composition; BRIEF, Behavior Rating Inventory of Executive Function; BSID-II, Bayley Scales of Infant Development 2; CANTAB, Cambridge Neuropsychological Test Automated Battery; CPT, Conner's Continuous Performance Test; ELEMENT, Early Life Exposure in Mexico to ENvironmental Toxicants; FFQ, Food Frequency Questionnaire; HOME, Home Observation for the Measurement of the Environment; IPAQ, Integrated Physical Activity Questionnaire; KXRF, k-X-ray fluorescence; WAIS, Wechsler Abbreviated Scale of Intelligence; iDXA, Intelligent Dual X-ray Absorptiometry.

levels during pregnancy and lactation, ${ }^{1851}$ and breastmilk lead concentrations. ${ }^{31}$

\section{Offspring neurobehavioural development}

Our studies confirmed the adverse effects of prenatal lead exposure on offspring cognitive development, ${ }^{52}$ with detectable adverse effects of lead exposure on cognition $^{53-55}$ and behavioural disorders,${ }^{42}$ even at low levels of exposure (eg, blood lead concentrations of $<5$ or $10 \mu \mathrm{g} /$ $\mathrm{dL}$ ). We also found that maternal self-esteem influences offspring mental and psychomotor development and may mitigate negative effects of lead exposure.$^{56}$ Genetic variants were also found to modify the relationship between lead exposure and early cognitive development. ${ }^{5758}$

\section{Growth, maturation, blood pressure and metabolism}

We found that higher cumulative prenatal lead exposure, as indicated by maternal bone lead levels, was associated with lower weight in boys but not girls during the first 5 years of life, ${ }^{59}$ with lower body mass index (BMI) and adiposity among boys and girls undergoing adolescence ${ }^{60}$ and with higher blood pressure in girls but not boys at $7-15$ years of age. ${ }^{61}$ Additionally, while maternal lead levels were not associated with offspring height, the child's own blood lead levels during infancy (birth to 24 months) predicted shorter stature at approximately 4 years of age ${ }^{62}$ but not child adiposity at $8-6$ years. ${ }^{60}$ Prenatal lead exposure was associated with delays in pubertal onset and progression in girls only. ${ }^{60} 63$

\section{Other toxicants}

\section{Other metals}

As ELEMENT evolved, its archived biorepository has been used to measure biomarkers of prenatal and postnatal exposure to an expanding range of additional toxicants. Among them have been other metals, including mercury, manganese and cadmium, as well as mixtures of metals. ${ }^{64}$ For example, mean levels of mercury in whole blood among ELEMENT mothers during pregnancy, cord blood and offspring children were three to five times greater than values reported in population surveys from the USA and Canada, ${ }^{65}$ with higher rates of consuming tuna and shark as suspected risk factors. Early childhood blood levels of manganese exhibited an inverted U-shaped relationship with mental development 
scores ${ }^{66}$ Sources of and descriptive statistics surrounding dietary cadmium have also been reported in mothers and children and related to lower adiposity among girls ${ }^{67}$ (see also, Diet).

\section{Endocrine disrupting chemicals}

ELEMENT investigators have also been examining exposures and impacts related to organics associated with plastics. So far, our studies indicate sex-specific effects of exposure to EDCs on metabolism. In boys, prenatal and concurrent exposure to certain phthalates predicted a more favourable lipid profile ${ }^{68}$ and lower adiposity ${ }^{69}$ during peripuberty. These unexpected results may reflect residual variability in pubertal progression. On the contrary, concurrent exposure to bisphenol A (BPA) was associated with subcutaneous adiposity in girls. ${ }^{69} \mathrm{In}$ studies of sexual maturation using physician-assessed Tanner staging and serum levels of sex hormones, ${ }^{70}$ prenatal exposure to phthalates correlated with slower pubertal development in boys. ${ }^{71}$ The opposite trend was observed in girls. ${ }^{73} 74$ Generally, cross-sectional relationships between peripubertal exposure to these EDCs and reproductive development were less robust than perinatal exposure..$^{71}$

\section{Pesticides}

Prenatal exposure to the pesticide chlorpyrifos, as reflected by measurement of 3, 5, 6-trichloro-2-pyridinol in maternal urine samples during pregnancy as a biomarker, was found to occur at levels moderately higher than those in the USA and to also be associated with an increased risk of symptoms of attention deficit hyperactivity disorder (ADHD) ${ }^{75}$

\section{Fluoride}

Finally, a programme of research on the potential neurotoxicity of early life exposure to fluoride was recently started, with initial findings suggesting that prenatal fluoride exposure is associated with reduced measures of intelligence ${ }^{76}$ as well as increased symptoms of ADHD in pre-school and elementary school age children. ${ }^{77}$ Additionally, urinary fluoride concentrations were cross-sectionally associated with later pubic hair growth and genital development in boys aged 10-17 years, but not significantly related to pubertal development in girls. ${ }^{78}$

\section{Diet}

A key feature of ELEMENT is the repeated dietary assessments in the mothers during pregnancy, in the mothers on behalf of their children during infancy and early childhood and in the children themselves from peripuberty onward. The associated data have been used to examine dietary influences on toxicant absorption and/or distribution, such as the finding that increased levels of maternal blood and bone lead are associated with low dietary calcium. ${ }^{45}$ A recent study reported positive correlations between intake of potatoes and urinary cadmium concentrations in children and positive correlations between dietary and urinary cadmium concentrations among mother-child dyads who were not exposed to smoking during pregnancy. ${ }^{79}$

Dietary factors have also been evaluated as modifiers of toxicant impacts. For example, child lead exposure was associated with lower stature, but only among individuals with zinc deficiency. ${ }^{80}$ In our more recent work, dietary factors are also being examined as primary determinant of outcomes of interest. We found that higher cumulative intake of sugar-sweetened beverage (SSB) during the first year of life was a determinant of abdominal and overall adiposity at $8-14$ years. ${ }^{81}$ During peripuberty, adherence to a prudent dietary pattern was protective against metabolic risk in boys, whereas a dietary pattern indicative of a transition towards a Westernised diet corresponded with higher adiposity among girls. ${ }^{82}$

\section{Mechanisms and mediators \\ Epigenetics and epigenomics}

DNA methylation has surfaced as a key mechanism linking early life exposures to later health outcomes. Higher maternal patella lead corresponded with higher methylation of genes involved in growth and metabolism in girls (cord blood IGF2 and HSD11B2).$^{83}$ Expanding our analyses to additional environmental exposures-namely, BPA and phthalates-during multiple sensitive periods (in utero, early childhood, peripuberty) revealed differential relations of each exposure with methylation of several candidate genes during peripuberty. ${ }^{84}$ The extent to which differential methylation of these regions mediate exposure/outcome relationships ${ }^{85}$ and the role of environmental deflection of age-related DNA methylation changes ${ }^{86}$ are upcoming areas of interest.

\section{Metabolomics}

The ELEMENT cohort has untargeted metabolomics data assayed from fasting blood collected in ELEMENT 2011 and 2015, as well as targeted metabolomics data on amino acids and acylcarnitines in ELEMENT 2011. So far, we have identified compounds involved in lipid, amino acid and DNA pathways that were associated with higher metabolic syndrome risk in ELEMENT $2011,{ }^{87}$ as well as a some metabolites associated with SSB intake that are also markers of elevated blood pressure during adolescence. ${ }^{88}$

\section{Ethnography}

In the ELEMENT 2014 ('Mexican Exposures'), intensive ethnographic observation of six families in two distinct Mexico City neighbourhoods emphasised the importance of neighbourhood environments for health. ${ }^{89}$ Our work in this area provides insights into how neoliberal economic processes (eg, the North American Free Trade Agreement) transformed the food landscape in Mexico to one composed primarily of processed foods. We have also unveiled a key role of the extended family household structure in diet-related factors, from food preparation to mealtime behaviours. ${ }^{89}$ 


\section{Statistical methods development}

Given the complex data structure in the ELEMENT study, including longitudinal follow-up, multiple exposures and high-dimensional data, ELEMENT has served as fertile ground for statistical methods development and innovations in data sharing. To date, methods arising from ELEMENT data include: structural equation models ${ }^{90-93}$; models to identify timing of vulnerability ${ }^{94}$; methods for gene-environment interactions in the context of multiple correlated exposures ${ }^{95}{ }^{96}$; methods to identify complex interactions among multiple exposures, ${ }^{97}$ metabolomics determinants of metabolic risk, ${ }^{87}$ methods to characterise growth trajectories ${ }^{20} 98$ and derive dietary patterns ${ }^{19}$; and methods for data integration across multiple cohorts. ${ }^{99} 100$ Current and ongoing work involves the use of novel dimension reduction and simulation techniques to analyse accelerometry and dental imaging data.

\section{FUTURE RESEARCH}

In addition to continuing research involving the longterm follow-up of the mothers and children recruited as part of the original three cohorts, future plans include recruitment of grandchildren given that the original 'child' participants are now becoming parents. We recently received funds from a cohort maintenance grant to maintain and enrich resource infrastructure for existing environmental epidemiology cohorts. The overarching goals of this proposal are to investigate associations of exposure to EDCs during multiple sensitive periods of development from conception through middle-age with metabolic and reproductive health, to elucidate both within-generational and inter-generational biological pathways via epigenetic and microbiome pathways and to develop novel data management techniques and methods to improve data integration, data-sharing and cross-institute data communication to enrich the existing ELEMENT database. In parallel, we will collect data from the original mothers (ie, women in cohorts 1-3) on their cardiometabolic health as they progress through the perimenopausal transition in order to gain insight into the effects of toxicant exposure during pregnancy on longterm postpartum health.

\section{STRENGTHS AND LIMITATIONS}

Key strengths of ELEMENT include in-person collection of exposure and outcome measures using researchquality standard protocols, an extensive biorepository of specimens from gestation through adolescence, rich covariate data including physician-assessed pubertal status, newly collected high-dimensional 'omics data and ethnographical data-all within a long-term study of early lead exposure that will soon span three generations. Together, these data make ELEMENT uniquely poised to carry out a broad range of research, from technical multi-'omics studies to mixed-methods analyses leveraging the ethnography data. Research projects within ELEMENT are predominantly led by students and trainees in the USA and Mexico, thereby forging fruitful international collaborations and mentorship.

This cohort also has several weaknesses. First, we have limited information on maternal perinatal conditions, with data on prepregnancy BMI in a small subset of mothers and no information on maternal glycaemia. Thus, in analyses where these characteristics may confound associations of interest, we acknowledge the potential for unmeasured confounding by maternal weight status and/or gestational glucose tolerance, ${ }^{101}$ and in more recent in-progress analyses, we use first trimester BMI as a proxy for prepregnancy BMI given evidence of a decent correlation between the two measures. ${ }^{102}$ Second, we have a limited remaining volume of early archived biosamples to explore new questions given the ongoing and long-term nature of ELEMENT. Third, we have limited information on the children's biological fathers, which restricts our ability to study the contribution of paternal characteristics to developmental origins of health and disease. Finally, given that our cohort is entirely Hispanic, our findings may not be generalisable to other race/ethnicities-a weakness that we are careful to mention with each study.

\section{COLLABORATION}

Interested investigators should submit a proposal including an analysis plan to the core group of ELEMENT co-investigators, which meets bimonthly. The discussion among the co-investigator team ensures that the outside investigator has adequate knowledge of the data, understands how the proposed analysis relates to previous analyses to avoid scientific overlap between projects and optimise use of scarce resources. Once an analysis plan is approved, the data manager creates a deidentified dataset for secondary analysis. We encourage collaborations that make use of the unique structure of ELEMENT comprising long-term follow-up of a well-characterised mother-child population in a setting with relatively high toxicant exposure. Investigators interested in working with ELEMENT data can contact the ELEMENT PIs KEP at karenep@umich.edu and M-MT-R at mmtellez@insp.mx.

\section{Author affiliations}

${ }^{1}$ Department of Epidemiology, Colorado School of Public Health, University of Colorado Denver Anschutz Medical Center, Aurora, Colorado, USA

${ }^{2}$ Department of Nutritional Sciences, University of Michigan School of Public Health, Ann Arbor, Michigan, USA

${ }^{3}$ Lifecourse Epidemiology of Adiposity and Diabetes (LEAD) Center, Colorado School of Public Health, University of Colorado Denver Anschutz Medical Center, Aurora, Colorado, USA

${ }^{4}$ National Council of Science and Technology, National Institute of Public Health, Mexico City, Mexico

${ }^{5}$ Department of Biostatistics, University of Michigan School of Public Health, Ann Arbor, Michigan, USA 
${ }^{6}$ Department of Environmental Health Sciences, University of Michigan School of Public Health, Ann Arbor, Michigan, USA

${ }^{7}$ Center for Human Growth and Development, University of Michigan, Ann Arbor, MI, United States

${ }^{8}$ Department of Anthropology, University of Michigan, Ann Arbor, Michigan, USA ${ }^{9}$ Department of Cariology, Operative Dentistry and Dental Public Health, Indiana University School of Dentistry, Indianapolis, Indiana, USA

${ }^{10}$ Center for Population Health Research, National Institute of Public Health,

Cuernavaca, Mexico

${ }^{11}$ Department of Environmental Medicine \& Public Health, Icahn School of Medicine at Mount Sinai Hospital, New York, New York, USA

${ }^{12}$ Division of Research in Community Interventions, Instituto Nacional de Perinatologia, Mexico City, Mexico

${ }^{13}$ Center for Nutrition and Health Research, National Institute of Public Health, Cuernavaca, Mexico

${ }^{14}$ Department of Environmental and Occupational Health, University of Washington School of Public Health, Seattle, Washington, USA

${ }^{15}$ Dirección de Prestaciones Económicas y Sociales, Mexican Institute of Social Security, Mexico City, Mexico

Acknowledgements We are grateful for Drs Don Smith and Teresita Gonzalez de Cossio for their contributions to the ELEMENT cohorts and the American British Cowdray Medical Centre in Mexico City for providing us with research facilities.

Contributors WP and MT- 0 conceived manuscript idea, wrote the initial draft of the paper and incorporated co-author comments. HH, MH-A, M-MT-R and KEP contributed funding, reagents and materials for original three cohorts and major follow-up studies (ELEMENT 2011 and 2015). LT, BS, AC, JM, DD, ER, EAM-M, HL-F, PS, AE, RW, MA, LS, DW, JG, RL, MS-G, LFB-A, AM-G, HH, MH-A, M-MT-R and KEP read various drafts of the manuscript, provided critical feedback and approved the final version for submission.

Funding This work was supported by the National Institutes of Environmental Health Sciences at the National Institutes of Health (P42ES05947, K23ES000381, P01ES022844, P30DK089503, P30ES00002, R01ES014930, R01ES07821, R24DK097153, R24ES028502, R01ES024732, R01ES021446, P30ES017885, R01ES013744, K01ES014907, K01ES016587, P42ES016454), the US Environmental Protection Agency (RD83543601); Consejo Nacional de Ciencia y Tecnologia (106565, 261063, 29192-M, 37210-M, 41912-M); and Consejo de Estudios para la Restauración y Valoración Ambiental (CONSERVA), Departamento del Distrito Federal, México. National Science Foundation (NSF) 1744724 and 1430391. The funders did not play any role in the conception or writing of this paper (or any others from the ELEMENT Project).

Competing interests None.

Provenance and peer review Not commissioned; externally peer reviewed.

Data availability statement Data are available upon reasonable request.

Open access This is an open access article distributed in accordance with the Creative Commons Attribution Non Commercial (CC BY-NC 4.0) license, which permits others to distribute, remix, adapt, build upon this work non-commercially, and license their derivative works on different terms, provided the original work is properly cited, appropriate credit is given, any changes made indicated, and the use is non-commercial. See: http://creativecommons.org/licenses/by-nc/4.0/.

\section{REFERENCES}

1. Bellinger D, Leviton A, Waternaux C, et al. Longitudinal analyses of prenatal and postnatal lead exposure and early cognitive development. N Engl J Med 1987;316:1037-43.

2. Cummins SK, Goldman LR. Even advantaged children show cognitive deficits from low-level lead toxicity. Pediatrics 1992:90:995-7.

3. Fergusson DM, Horwood LJ. The effects of lead levels on the growth of word recognition in middle childhood. Int $\mathrm{J}$ Epidemiol 1993;22:891-7.

4. Needleman HL, Schell A, Bellinger D, et al. The long-term effects of exposure to low doses of lead in childhood. An 11-year follow-up report. N Engl J Med 1990;322:83-8.

5. Silbergeld EK. Lead in bone: implications for toxicology during pregnancy and lactation. Environ Health Perspect 1991;91:63-70.

6. Gulson BL, Mahaffey KR, Jameson CW, et al. Mobilization of lead from the skeleton during the postnatal period is larger than during pregnancy. J Lab Clin Med 1998;131:324-9.
7. Smith DR, Flegal AR. Lead in the biosphere: recent trends. Ambio 1995;24:21-3.

8. Tong S, von Schirnding YE, Prapamontol T. Environmental lead exposure: a public health problem of global dimensions. Bull World Health Organ 2000;78:1068-77.

9. Driscoll W, Mushak P, Garfias J, et al. Reducing lead in gasoline. Mexico's experience. Environ Sci Technol 1992;26:1702-5.

10. Gulson BL, Jameson CW, Mahaffey KR, et al. Pregnancy increases mobilization of lead from maternal skeleton. $J$ Lab Clin Med 1997;130:51-62.

11. Lagerkvist BJ, Ekesrydh S, Englyst V, et al. Increased blood lead and decreased calcium levels during pregnancy: a prospective study of Swedish women living near a smelter. Am J Public Health 1996;86:1247-52.

12. Barker DJ, Gluckman PD, Godfrey KM, et al. Fetal nutrition and cardiovascular disease in adult life. Lancet 1993;341:938-41.

13. Barker DJ, Osmond C. Infant mortality, childhood nutrition, and ischaemic heart disease in England and Wales. Lancet 1986;1:1077-81.

14. Barker DJ, Winter PD, Osmond C, et al. Weight in infancy and death from ischaemic heart disease. Lancet 1989;2:577-80.

15. Weinhold B. Lead in Mexican children: Pottery use slows reductions in blood. Environ Health Perspect 2004;112:A569-A.

16. Schnaas L, Rothenberg SJ, Flores M-F, et al. Blood lead secular trend in a cohort of children in Mexico City (1987-2002). Environ Health Perspect 2004;112:1110-5.

17. Hu H, Milder FL, Burger DE. The use of K x-ray fluorescence for measuring lead burden in epidemiological studies: high and low lead burdens and measurement uncertainty. Environ Health Perspect 1991;94:107-10.

18. Hernandez-Avila M, Gonzalez-Cossio T, Hernandez-Avila JE, et al. Dietary calcium supplements to lower blood lead levels in lactating women: a randomized placebo-controlled trial. Epidemiology 2003;14:206-12.

19. Jansen EC, Zhou L, Perng W, et al. Vegetables and lean proteinsbased and processed meats and refined grains -based dietary patterns in early childhood are associated with pubertal timing in a sex-specific manner: a prospective study of children from Mexico City. Nutr Res 2018;56:41-50.

20. Baek J, Zhu B, Song PXK. Bayesian analysis of infant's growth dynamics with in utero exposure to environmental toxicants. Ann Appl Stat 2019;13:297-320.

21. Tang L, Zhou L, Song PXK. Fusion learning algorithm to combine partially heterogeneous COX models. Comput Stat 2019;34:395-414

22. Tang L, Song PX. Fused LASSO approach in regression coefficients clustering learning parameter heterogeneity in data integration. Journal of machine learning research: JMLR 2016;17:1-23.

23. Salud Sde, ambiental S. Limitaciones $Y$ especificaciones sanitarias para El uso de Los compuestos de plomo 2000.

24. Salud Sde, ambiental S. Limitaciones $Y$ especificaciones sanitarias para El uso de Los compuestos de plomo 2013.

25. American Academy of Pediatrics Committee on Environmental Health. Lead exposure in children: prevention, detection, and management. Pediatrics 2005;116:1036-46.

26. U.S. Department of Health and Human Services, Centers for Disease Control and Prevention. Preventing lead poisoning in young children. Atlanta: CDC, 2005.

27. Centers for Disease Control and Prevention. Interpreting and managing blood lead leavels $<10 \mathrm{ug} / \mathrm{dL}$ in children and reducing childhood exposures to lead. CDC, 2007Contract No: RR08.

28. Centers for Disease Control and Prevention. Guidelines for the identification and management of lead exposure in pregnant and lactating women. Atlanta: U.S. Department of Health and Human Services, 2010

29. Roberts EFS. Bio-ethnography: a collaborative, methodological experiment in Mexico City: Somatosphere, 2015. Available: http:// somatosphere.net/2015/02/bio-ethnography.html [Accessed cited 19 Feb 2018].

30. Roberts EFS, Sanz C. Bioethnography: a how-to guide for the twentieth century. In: Meloni M, ed. The Palgrave Handbook of biology and society. London: Springer, 2017.

31. Ettinger AS, Téllez-Rojo MM, Amarasiriwardena C, et al. Influence of maternal bone lead burden and calcium intake on levels of lead in breast milk over the course of lactation. Am J Epidemiol 2006;163:48-56.

32. Smith D, Hernandez-Avila M, Téllez-Rojo MM, et al. The relationship between lead in plasma and whole blood in women. Environ Health Perspect 2002;110:263-8.

33. Lamadrid-Figueroa $\mathrm{H}$, Téllez-Rojo MM, Hernández-Avila M, et al. Association between the plasma/whole blood lead ratio and history 
of spontaneous abortion: a nested cross-sectional study. BMC Pregnancy Childbirth 2007;7:22.

34. Lamadrid-Figueroa H, Téllez-Rojo MM, Hernández-Cadena L, et al. Biological markers of fetal lead exposure at each stage of pregnancy. J Toxicol Environ Health A 2006;69:1781-96.

35. Ettinger AS, Téllez-Rojo MM, Amarasiriwardena C, et al. Levels of lead in breast milk and their relation to maternal blood and bone lead levels at one month postpartum. Environ Health Perspect 2004;112:926-31.

36. Aro AC, Todd AC, Amarasiriwardena C, et al. Improvements in the calibration of $109 \mathrm{Cd} \mathrm{K} \mathrm{x}$-ray fluorescence systems for measuring bone lead in vivo. Phys Med Biol 1994;39:2263-71.

37. Hernández-Avila M, Romieu I, Parra S, et al. Validity and reproducibility of a food frequency questionnaire to assess dietary intake of women living in Mexico City. Salud Publica Mex 1998;40:133-40.

38. B N. Bayley scales of infant development manual. 2 ed. San Antonio, TX: The Psychological Corporation, 1993.

39. M D. McCarrthy scales of children abilities. Madrid, Spain: TEA ediciones, 2009.

40. Wechsler D. WAIS-R: Wechsler adult intelligence Salce-Revised. New York, NY: Psychological Corporation, 1981.

41. Behavior assessment system for children. The Corsini encyclopedia of psychology:1-2.

42. Huang S, Hu H, Sánchez BN et al. Childhood blood lead levels and symptoms of attention deficit hyperactivity disorder (ADHD): a cross-sectional study of Mexican children. Environ Health Perspect 2016;124:868-74

43. Brown MJ, Hu H, Gonzales-Cossio T, et al. Determinants of bone and blood lead concentrations in the early postpartum period. Occup Environ Med 2000;57:535-41.

44. Téllez-Rojo MM, Hernández-Avila M, Lamadrid-Figueroa $\mathrm{H}$, et al. Impact of bone lead and bone resorption on plasma and whole blood lead levels during pregnancy. Am J Epidemiol 2004;160:668-78.

45. Hernandez-Avila M, Gonzalez-Cossio T, Palazuelos E, et al. Dietary and environmental determinants of blood and bone lead levels in lactating postpartum women living in Mexico City. Environ Health Perspect 1996;104:1076-82.

46. Téllez-Rojo MM, Hernández-Avila M, González-Cossío T, et al. Impact of breastfeeding on the mobilization of lead from bone. Am $J$ Epidemiol 2002;155:420-8.

47. González-Cossío T, Peterson KE, Sanín LH, et al. Decrease in birth weight in relation to maternal bone-lead burden. Pediatrics 1997; 100:856-62

48. Sanín LH, González-Cossío T, Romieu I, et al. Effect of maternal lead burden on infant weight and weight gain at one month of age among breastfed infants. Pediatrics 2001;107:1016-23.

49. Ettinger AS, Roy A, Amarasiriwardena CJ, et al. Maternal blood, plasma, and breast milk lead: lactational transfer and contribution to infant exposure. Environ Health Perspect 2014;122:87-92.

50. Janakiraman V, Ettinger A, Mercado-Garcia A, et al. Calcium supplements and bone resorption in pregnancy: a randomized crossover trial. Am J Prev Med 2003;24:260-4.

51. Ettinger AS, Hu H, Hernandez-Avila M. Dietary calcium supplementation to lower blood lead levels in pregnancy and lactation. J Nutr Biochem 2007:18:172-8.

52. Gomaa $\mathrm{A}, \mathrm{Hu} \mathrm{H}$, Bellinger $\mathrm{D}$, et al. Maternal bone lead as an independent risk factor for fetal neurotoxicity: a prospective study. Pediatrics 2002;110:110-8.

53. Téllez-Rojo MM, Bellinger DC, Arroyo-Quiroz C, et al. Longitudinal associations between blood lead concentrations lower than 10 microg/dL and neurobehavioral development in environmentally exposed children in Mexico City. Pediatrics 2006;118:e323-30.

54. Braun JM, Hoffman E, Schwartz J, et al. Assessing windows of susceptibility to lead-induced cognitive deficits in Mexican children. Neurotoxicology 2012;33:1040-7.

55. Hu H, Téllez-Rojo MM, Bellinger D, et al. Fetal lead exposure at each stage of pregnancy as a predictor of infant mental development. Environ Health Perspect 2006;114:1730-5.

56. Surkan PJ, Schnaas L, Wright RJ, et al. Exposure to lead, and child neurodevelopment. Neurotoxicology 2008;29:278-85.

57. Kordas K, Ettinger AS, Bellinger DC, et al. A dopamine receptor (DRD2) but not dopamine transporter (DAT1) gene polymorphism is associated with neurocognitive development of Mexican preschool children with lead exposure. J Pediatr 2011;159:638-43.

58. Pilsner JR, $\mathrm{Hu} \mathrm{H}$, Wright RO, et al. Maternal MTHFR genotype and haplotype predict deficits in early cognitive development in a lead-exposed birth cohort in Mexico City. Am J Clin Nutr 2010;92:226-34.
59. Afeiche M, Peterson KE, Sánchez BN, et al. Prenatal lead exposure and weight of 0- to 5-year-old children in Mexico City. Environ Health Perspect 2011;119:1436-41.

60. Liu Y, Peterson KE, Montgomery K, et al. Early lead exposure and childhood adiposity in Mexico City. Int J Hyg Environ Health 2019;222:965-70.

61. Zhang A, Hu H, Sánchez BN, et al. Association between prenatal lead exposure and blood pressure in children. Environ Health Perspect 2012;120:445-50.

62. Afeiche M, Peterson KE, Sánchez BN, et al. Windows of lead exposure sensitivity, attained height, and body mass index at 48 months. J Pediatr 2012;160:1044-9.

63. Jansen EC, Zhou L, Song PXK, et al. Prenatal lead exposure in relation to age at menarche: results from a longitudinal study in Mexico City. J Dev Orig Health Dis 2018;9:467-72.

64. Lewis RC, Meeker JD, Basu N, et al. Urinary metal concentrations among mothers and children in a Mexico City birth cohort study. Int $J$ Hyg Environ Health 2018;221:609-15.

65. Basu N, Tutino R, Zhang Z, et al. Mercury levels in pregnant women, children, and seafood from Mexico City. Environ Res 2014;135:63-9.

66. Claus Henn B, Schnaas L, Ettinger AS, et al. Associations of early childhood manganese and lead coexposure with neurodevelopment. Environ Health Perspect 2012;120:126-31.

67. Moynihan M, Telléz-Rojo MM, Colacino J, et al. Prenatal cadmium exposure is negatively associated with adiposity in girls not boys during adolescence. Front Public Health 2019;7.

68. Perng W, Watkins DJ, Cantoral A, et al. Exposure to phthalates is associated with lipid profile in peripubertal Mexican youth. Environ Res 2017;154:311-7.

69. Yang TC, Peterson KE, Meeker JD, et al. Bisphenol A and phthalates in utero and in childhood: association with child BMl z-score and adiposity. Environ Res 2017;156:326-33.

70. Chavarro JE, Watkins DJ, Afeiche MC, et al. Validity of SelfAssessed sexual maturation against physician assessments and hormone levels. J Pediatr 2017;186:172-8.

71. Ferguson KK, Peterson KE, Lee JM, et al. Prenatal and peripubertal phthalates and bisphenol $A$ in relation to sex hormones and puberty in boys. Reprod Toxicol 2014;47:70-6.

72. Watkins DJ, Sánchez BN, Téllez-Rojo MM, et al. Impact of phthalate and BPA exposure during in utero windows of susceptibility on reproductive hormones and sexual maturation in peripubertal males. Environ Health 2017;16.

73. Watkins DJ, Sánchez BN, Téllez-Rojo MM, et al. Phthalate and bisphenol a exposure during in utero windows of susceptibility in relation to reproductive hormones and pubertal development in girls. Environ Res 2017;159:143-51.

74. Watkins DJ, Téllez-Rojo MM, Ferguson KK, et al. In utero and peripubertal exposure to phthalates and BPA in relation to female sexual maturation. Environ Res 2014;134:233-41.

75. Fortenberry GZ, Meeker JD, Sánchez BN, et al. Urinary 3,5,6-trichloro-2-pyridinol (TCPY) in pregnant women from Mexico City: distribution, temporal variability, and relationship with child attention and hyperactivity. Int $\mathrm{J}$ Hyg Environ Health 2014;217:405-12

76. Bashash $\mathrm{M}$, Thomas $\mathrm{D}, \mathrm{Hu} \mathrm{H}$, et al. Prenatal fluoride exposure and cognitive outcomes in children at 4 and $6-12$ years of age in Mexico. Environ Health Perspect 2017;125:097017.

77. Bashash $\mathrm{M}$, Marchand $\mathrm{M}, \mathrm{Hu} \mathrm{H}$, et al. Prenatal fluoride exposure and attention deficit hyperactivity disorder (ADHD) symptoms in children at 6-12 years of age in Mexico City. Environ Int 2018:121:658-66

78. Liu Y, Téllez-Rojo M, Hu H, et al. Fluoride exposure and pubertal development in children living in Mexico City. Environmental Health 2019;18.

79. Moynihan M, Peterson KE, Cantoral A, et al. Dietary predictors of urinary cadmium among pregnant women and children. Sci Total Environ 2017:575:1255-62

80. Cantoral A, Téllez-Rojo MM, Levy TS, et al. Differential association of lead on length by zinc status in two-year old Mexican children. Environ Health 2015;14.

81. Cantoral A, Téllez-Rojo MM, Ettinger AS, et al. Early introduction and cumulative consumption of sugar-sweetened beverages during the pre-school period and risk of obesity at 8-14 years of age. Pediatr Obes 2016;11:68-74.

82. Perng W, Fernandez C, Peterson KE, et al. Dietary patterns exhibit sex-specific associations with adiposity and metabolic risk in a cross-sectional study in urban Mexican adolescents. J Nutr 2017;147:1977-85

83. Goodrich JM, Sánchez BN, Dolinoy DC, et al. Quality control and statistical modeling for environmental epigenetics: a study on in 
utero lead exposure and DNA methylation at birth. Epigenetics 2015;10:19-30.

84. Goodrich JM, Dolinoy DC, Sánchez BN, et al. Adolescent epigenetic profiles and environmental exposures from early life through peri-adolescence. Environ Epigenet 2016;2:dvw018-dvw.

85. Bowman A, Peterson KE, Dolinoy DC, et al. Phthalate exposures, DNA methylation and adiposity in Mexican children through adolescence. Front Public Health 2019;7.

86. Kochmanski J, Montrose L, Goodrich JM, et al. Environmental deflection: the impact of toxicant exposures on the aging epigenome. Toxicol Sci 2017;156:325-35.

87. Perng W, Hector EC, Song PXK, et al. Metabolomic determinants of metabolic risk in Mexican adolescents. Obesity 2017;25:1594-602.

88. Perng W, Tang L, Song PXK, et al. Urate and nonanoate mark the relationship between sugar-sweetened beverage intake and blood pressure in adolescent girls: a metabolomics analysis in the element cohort. Metabolites 2019;9:100.

89. Roberts EFS. What gets inside: violent entanglements and toxic boundaries in Mexico City. Cultural Anthropology 2017;32:592-619.

90. Sánchez BN, Budtz-Jørgensen E, Ryan LM. An estimating equations approach to fitting latent exposure models with longitudinal health outcomes. Ann Appl Stat 2009;3:830-56.

91. Sánchez BN, Budtz-Jørgensen E, Ryan LM, et al. Structural equation models. J Am Stat Assoc 2005;100:1443-55.

92. Sánchez BN, Houseman EA, Ryan LM. Residual-based diagnostics for structural equation models. Biometrics 2009;65:104-15.

93. Sánchez BN, Kim S, Sammel MD. Estimators for longitudinal latent exposure models: examining measurement model assumptions. Stat Med 2017;36:2048-66.
94. Sánchez BN, Hu H, Litman HJ, et al. Statistical methods to study timing of vulnerability with sparsely sampled data on environmental toxicants. Environ Health Perspect 2011;119:409-15.

95. Sánchez BN, Kang S, Mukherjee B. A latent variable approach to study gene-environment interactions in the presence of multiple correlated exposures. Biometrics 2012;68:466-76.

96. Tao Y, Sánchez BN, Mukherjee B. Latent variable models for gene-environment interactions in longitudinal studies with multiple correlated exposures. Stat Med 2015;34:1227-41.

97. Ma S, Song PX-K. Varying index coefficient models. J Am Stat Assoc 2015;110:341-56.

98. Perng W, Baek J, Zhou CW, et al. Associations of the infancy body mass index peak with anthropometry and cardiometabolic risk in Mexican adolescents. Ann Hum Biol 2018:1-9.

99. Wang F, Song PX-K, Wang L. Merging multiple longitudinal studies with study-specific missing covariates: a joint estimating function approach. Biometrics 2015;71:929-40.

100. Tang L, Song PXK. Fused Lasso Approach in Regression Coefficients Clustering - Learning Parameter Heterogeneity in Data Integration. J Mach Learn Res 2016;17.

101. Carter M. Associations of maternal carbohydrate intake during pregnancy and adolescent adiposity and metabolic health [Master of Science. Ann Arbor, MI: University of Michigan School of Public Health, 2018.

102. Krukowski RA, West DS, DiCarlo M, et al. Are early first trimester weights valid proxies for preconception weight? BMC Pregnancy Childbirth 2016;16:357. 